\title{
O VIDENTE AMÓS E A POLÍTICA: CONTEXTOS DO SUL DO LEVANTE PARA ESTUDOS NO LIVRO DE AMÓS
}

\section{The seer Amos and politics: Southern Levante contexts for studies in the Book of Amos}

\author{
João Batista Ribeiro Santos ${ }^{1}$
}

\begin{abstract}
RESUMO
Antigos postulados acerca do Livro de Amós alçaram o profeta a porta-voz dos pobres relativamente à monarquia como regime opressor, representada pelos reis de Israel Norte ("Reino do Norte"). Profeta e livro foram transformados em ícones da justiça social. Ao debater esses postulados na primeira parte, esta pesquisa indica seu objetivo de realizar, a partir da segunda parte, uma escala historiográfica do Levante no século VIII A.E.C. visando apresentar fontes, acontecimentos e contextos dos movimentos vitais envolvendo o domínio do império neoassírio, a política expansionista de Damasco e as pretensões comerciais israelitas na região. Nossa hipótese é que as profecias - nas quais "Amós" denota os escribas, em suas várias etapas de atualização e redação - representam reivindicações de grandes agricultores, excluídos de rede comercial, contra a tributação e o aumento de preços. Daí, a intenção de reformar o Estado e o culto em Israel Norte. Entendemos que a investigação das culturas e dos tratos políticos, que tiveram por cenário o sul do Levante e dizem respeito de alguma forma aos israelitas, contribuem para novas abordagens do Livro de Amós, especialmente para novos estudos interpretativos.
\end{abstract}

Palavras-chave: Livro de Amós; literatura profética; Bíblia Hebraica; antigo Israel.

\begin{abstract}
Ancient postulates about the Book of Amos raised the prophet to spokesman for the poor regarding the monarchy as an oppressive regime, represented by the kings of North Israel ("Northern Kingdom"). Prophet and book were transformed into icons of social justice. When discussing these postulates in the first part, this research indicates its objective to carry out, from the second part onwards, a historiographic scale of the Levant in the 8th century B.C.E. aiming to present sources, events and contexts of vital movements involving the rule of the Neo-Assyrian Empire, the expansionist policy of Damascus and the Israeli commercial intentions in the region. Our hypothesis is that the prophecies - in which "Amos" denotes the scribes, in its various stages of updating and writing - represent claims of large farmers, excluded from the commercial network, against taxation and price increases. Therefore, they intended to reform the State and worship in North Israel. We understand that the investigation of cultures and political dealings, which had the southern Levant as a backdrop and are in some way related to the Israelites, contribute to new approaches to the Book of Amos, especially for new interpretive studies.
\end{abstract}

Keywords: Book of Amos; prophetic literature; Hebrew Bible; ancient Israel.

\footnotetext{
${ }^{1}$ Docente e editor da Faculdade de Teologia da Universidade Metodista de São Paulo (Umesp). Pós-doutor em História Antiga pela Faculdade de Ciências e Letras da Universidade Estadual Paulista (FCL/Unesp), mestre e doutor em Ciências da Religião (Linha de pesquisa: Literatura e Religião no Mundo Bíblico) pela Universidade Metodista de São Paulo (Umesp) e mestre em História Política (Linha de pesquisa: História Antiga) pela Universidade do Estado do Rio de Janeiro (UERJ).

REVISTA RELEGENS THRÉSKEIA - 2021 - UFPR
} 


\section{Introdução}

Os protestos do vidente Amós inspiraram e dirigiram importantes pesquisas com dimensões enciclopédicas e panfletárias em seus vários propósitos; por isso, entendemos que mais do que citações das obras requer-se avaliação crítica nos domínios em que se propõe a produzir novas abordagens. Por vezes, resulta disso ao menos dois problemas: a ciência apropriada como suporte pouco acrescenta ao seu domínio específico por ser submetida ao uso parafrásico e o conteúdo invariavelmente permanece o mesmo pelo emprego de antigos sistemas. Outras naturezas, outras culturas, outras abordagens, assim possibilidade de novas descobertas!

Marshall Sahlins (2019, p. 28-29) alerta para o descontrole dos usos de determinado domínio científico pelo risco de lançá-lo ao “crepúsculo de sua carreira”. O Livro de Amós, que faz parte do Bíblia Hebraica ("Primeiro Testamento"), como obra literária, ilumina múltiplas fontes, por isso analisaremos algumas abordagens tradicionais, destacando evidências históricas vinculadas a Israel Norte ("Reino do Norte") ausentes das interpretações. Para o exercício exegético, o que mais importa são os contextos coetâneos, pois as fontes - o enunciado ou obra literária, no caso do manuscrito ou livro - são produções que têm função social. Pelo fato de os agentes históricos - inclusive o artefato em função de índice - influenciarem as linguagens, torna-se muito importante tomar conhecimento das representações de acontecimentos que contribuam para a interpretação do objeto de pesquisa.

Com efeito, apresentaremos contrapontos historicizantes aos antigos postulados, abrindo as profecias e panfletos de Amós no antigo Oriente-Próximo porque o avanço da Assíria em direção ao sul do Levante modificou num primeiro momento o quadro político pela imposição de governantes títeres (vassalos) e, num segundo momento, os limites citadinos do mapa geográfico. No século VIII, ${ }^{2}$ época de reinado de Jeroboam II (c. 783-743 [786-746]) e de atividade de Amós, essas mudanças dizem respeito a Israel Norte: ${ }^{3}$ o importante reino israelita se encontra em pleno desenvolvimento urbanístico e econômico - iniciado no reinado

\footnotetext{
${ }^{2}$ Acerca da datação, referimo-nos sempre a "antes da Era Comum" (A.E.C.), exceto quando houver informação específica.

${ }^{3}$ Desde o período de ascensão militar da Assíria com Assurnasirpal II (Aššur-nāṣir-apli, c. 883-857) até o “domínio do mundo", pelo menos no início do reinado de Tiglat-pileser III (744-727), os cercos, destruições, vassalagens e arbitragens assírias, no mapa das bordas entre o norte e o sul do Levante, visam programática e sequencialmente os quatro centros econômica e militarmente mais poderosos, a saber, o reino de Arpad/Bit-Agushi e as capitais reais de Hamat, Damasco e Samaria.
}

REVISTA RELEGENS THRÉSKEIA - 2021 - UFPR 
de Omri (885-874) -, participando de rotas comerciais no Mediterrâneo, e em conflito políticomilitar com a cidade-Estado de Damasco ${ }^{4}$ pela liderança no sul do Levante. Assim, nos contrapontos historicizantes abordaremos as complexas políticas, a serem desenvolvidas em sequência historiográfica em plano de fundo para chegar à realidade externa e no exame de materialidade histórica para uma prática exegética, onde a pesquisa da história poderá conduzir aos intensos contatos numa região militarizada e em acelerada urbanização. Contextualmente, o estilo do agente revelará as novas funções da profecia e do próprio ato divinatório, além das circunstâncias a que divergiam e confluíam.

\section{Em torno de uma história tradicional}

Quase meio século de desenvolvimento em Israel Norte, operacionalizado pela dinastia omrida e iniciado com a construção da cidade de Samaria (hebraico: Šōmərôn; assírio: Sāmirīna), a nova capital de Israel Norte ("Reino do Norte”; hebraico: Yiśrā'ēl; assírio: "māt sir'i-la-a-a; lê-se em egípcio: I.si.ri.ar, "grupo social”, e ysry·l ou $y s r y \cdot r$, "território"), é interrompido pela tomada do poder liderada pelo oficial militar Jehu (c. 842/1-814). Esse período também ficou marcado pelas várias campanhas das guarnições do império neoassírio comandadas pelo rei Shalmanasar III (858-824) e principalmente pela posterior provincialização dos Estados arameus, ou seja, da região siro-canaanita, desde Hamat a Judah e Edom, com novas demarcações em toda a costa do Mediterrâneo. Em seguida, a grande territorialização assíria do Levante tem início com o rei Tiglat-pileser III (744-727), em cerca de 740/738, e pode-se afirmar que teve em alguma medida o testemunho de Amós no final da sua atividade profética.

A Assíria se projetou no centro dos acontecimentos como uma contraparte ao papel desempenhado na região pelo Egito no Período de Amarna ${ }^{5}$ e que foi retomado em menor escala na Idade do Ferro II $;{ }^{6}$ no entanto, desde o colapso da Idade do Bronze Tardio, em cerca de 1180, os reis que herdaram as políticas do Reino Novo hitita e a linhagem dinástica assíria estabelecida pelo rei Tiglat-pileser I (c. 1114-1076) permaneceram no Levante. Dos Estados herdeiros, suas atividades não avançaram tanto numa medida que pudessem impedir os contatos

\footnotetext{
${ }^{4}$ Damasco foi integrada a Aram, tornando-se o reino unido de Aram-Damasco no início do reinado de Hazael, $c$. $844 / 843$.

${ }^{5}$ Período baseado nos cerca de 382 documentos em tabletes de argila do arquivo das relações internacionais do faraó Akhenaton ou Amenhotep IV (c. 1353/1352-1336) e sua capital Akhetaton, o moderno sítio El-Amarna.

${ }^{6}$ Sobre isto, sugiro uma pesquisa recente sobre a presença egípcia e kushita nos conflitos envolvendo Assíria e Judah no final do século VIII (FRANKLIN, 2018).
} 
do Egito com os seus antigos Estados aliados no Mediterrâneo, para onde os pelishtim migraram no final da Idade do Bronze Tardio e construíram uma nova estrutura estatal.

Do período da expansão imperial até o domínio mundial, a partir de cerca de 880 (cf. MIEROOP, 2020), com as mudanças estruturais posteriormente dirigidas por Tiglat-pileser III, fica consolidado o domínio da presença militar assíria. Os Estados independentes e pequenos reinos não apenas pagavam tributos, mas muitos deles passaram a sofrer intervenção direta por garantias tributárias; isso ocorria mesmo quando eram governados por elites palaciais, pois esses reis locais eram transformados em títeres. Milton Schwantes (2008, p. 38), explanando acerca da superioridade militar assíria nesse período, destaca a sua capacidade de utilização do ferro e a moldagem laminada destinada a diversos usos, o que proporciona maior produção agrícola, armamentos e proteção militares.

Decerto, as cidades-Estado em que o governante obtém possibilidades de interação, seja por meio do comércio, seja por meio das relações políticas com reinos vizinhos, ou contato ocasionado em conflito de demarcação territorial, acrescentam ao seu cotidiano as culturas materiais e imateriais adquiridas, reservando um arsenal de artefatos destinados a expandir seus limites. Schwantes cita Amós 1-2 para postular um paralelo entre Israel Norte e Assíria quanto ao desenvolvimento: "sabemos que países da área da Síria e até mais ao norte (Ásia Menor) passavam por um processo semelhante de muita expansão territorial", beneficiados pelo excedente da produção agrícola (2008, p. 40). No entanto, Amós não se refere a nenhuma cidade da Anatólia, conhece a costa do Levante: cita as cidades-Estado de Gaza, ao sul, e Tiro, ao norte, localizadas no Mediterrâneo.

Luis Alonso Schökel e José Luiz Sicre Díaz (1991, p. 981) afirmam que Amós é o primeiro "profeta" a transmitir a sua mensagem por escrito; diferente, Frank Crüsemann (2009, p. 199-220) considera o conjunto redacional dos capítulos 4-11 do livro do profeta Oseias como a narrativa profética mais antiga da Bíblia Hebraica. ${ }^{7}$ Compreensivelmente, os compiladores da profecia de Amós desconhecem as cidades-Estado herdeiras do Reino Novo hitita localizadas no noroeste da Síria e na Anatólia. As fontes de Hattusha (Hattuša, capital do império hitita, localizada na Anatólia central; atual Boğazköy), capital do império de Hatti (Hatti; acádio: KUR URU Hatti, “Terra de Hatti”), indicam atividades expansionistas dos hititas em direção ao

\footnotetext{
${ }^{7}$ Schmid (2013, p. 121-25) classifica a profecia de Oseias e Amós como "escriturística"; quanto à profecia de Oseias, o especialista refere-se à redação iniciada em Oseias 4.1 (Oseias 4-9); Crüsemann (2009, p. 220) sublinha “o fato de nenhuma das 'passagens obscuras' dos capítulos 4-11 se referir a Judá!”. As atualizações judaítas e judaicas ao Livro de Amós permeiam as camadas literárias; no Livro de Oseias, as atualizações fazem parte de conjuntos editoriais específicos, em 1-3 e 12-14.
} 
Levante desde o reinado de Shuppiluliuma I (c. 1344-1322) (cf. MIEROOP, 2020, p. 211-20). Após o repentino colapso do império, alguns Estados, fragmentados politicamente, mantiveram suas interações na região siro-canaanita.

Com efeito, a formação de guarnições de defesa depende menos da produção quanto mais o governante tem o controle sobre as terras, pois parte do que se produz destina-se às elites governantes. Por outro lado, o expansionismo, ou pelo menos as iniciativas destinadas a isso, faz parte das atividades regulares também de líderes de grandezas socioétnicas tribais mesmo que os seus mecanismos funcionem sem as estruturas palaciais de controle de bens e pessoal (exército organizado, templo central, controle e taxação do acesso a água, sistema tributário da produção, propriedade e cessão da terra, burocracia palacial).

Para Schwantes (2008, p. 39), o "sistema de províncias" implantado pela Assíria é pouco eficiente porque sua burocracia seria operada pelo exército. Schwantes não informa as suas fontes quando emprega números estatísticos e cronológicos, mas é difícil atestar a presença de governante provincial não militar designado pela Assíria; as exceções à regra são os casos de entronização de parentes do rei. Caso que confirma a regra, Shamshi-ilu, comandante-chefe (turtānu) de Adad-nerari III, foi o importante agente administrativo e diplomático no Levante que liderou arbitragens e implantação de províncias assírias; ele governava Til-Barsip, antiga cidade levantina de origem hitita conquistada por Shalmanasar III e atual Tell Ahmar.

Mesmo em relação à vinculação entre religião ou o seu monumento, o templo, e o rei ou seu representante monumental, o palácio, não apresenta nenhuma novidade sequer quando comparada com as sociedades tribais siro-canaanitas. Na realidade, nessas sociedades a monumentalidade da religião costumava fazer parte do ordenamento das obras públicas oficiais ou comunitárias, sendo que os templos, não raro, mantinham em suas dependências oficinas onde os eruditos locais faziam, dentre outras tarefas intelectuais, o registro literário e artístico das realizações dos governantes.

De outro lado, os relevos e narrativas não encobrem completamente os conflitos internos entre líderes, com isso se acessa a rede de interesses. Jorge Pixley (1991, p. 51) chega a uma postulação interessante quando afirma que o aumento de tributos no comércio, denunciado pelo vidente Amós, seria de interesse dos mercadores porque eles "podem ter sido funcionários do Estado ou agentes livres". Sim, uma coisa e outra estão corretas, mas identificamos o estabelecimento das relações comerciais nesse modelo na Idade do Bronze Tardio na cidade mediterrânea de Ugarit, concluindo, portanto, que o antigo Israel deve ser estudado como parte da geografia política do Levante. 
Diante da realidade ao mesmo tempo estrutural e social do comércio que impede a vivência plena de importante parcela de agricultores e comerciantes, em parte diferente do que fora entendido por Pixley (1991, p. 51), Amós ${ }^{8}$ nem "revela a vinculação do santuário à Coroa" nem é possível chegar a indícios de que "os sacerdotes sentiam-se endividados com o rei por causa da restauração feita depois da perseguição desencadeada pela dinastia de Amri [Omri]”. Em uma mesma sequência enunciativa, Pixley defende pontos de vista difíceis de serem conciliados, isto é, os "abusos" dos comerciantes de alguma forma ligados à administração palacial e o que Amós "revela", a "vinculação do santuário à Coroa" e os sacerdotes "endividados" com o rei. Motivo: nos Estados com governo centralizado os templos ou santuários e seu panteão sempre estiveram vinculados ao rei, que pode inclusive trocar de divindade líder do panteão por dizer respeito à sua própria crença e espaço de interesse. Portanto, inexiste algo a ser revelado quando as relações sempre estiveram expostas no âmbito do político.

Ao realizar a análise exegética da camada literária nuclear e indubitavelmente histórica de Amós 7.10-17, Schwantes (2004, p. 52) coloca no plano historiográfico os discípulos do vidente como organizadores do livro, de forma especial dos panfletos proclamados como se fora experiências coletivas. ${ }^{9}$ Couberam a eles a preservação e a proclamação da profecia de Amós que confronta pessoas de moral. Nesse sentido, para Schwantes (2004, p. 42), são anunciadas ao público dois programas: "a do vidente e a do sacerdote, a de Amós e a de Amasias, a da crítica ao Estado e a do serviço a ele, a do campo e a da cidade". Acontece que esse antagonismo à maneira de dualidades requer ressalvas porque na Bíblia Hebraica fora preservado seguimento de líderes ruralistas a militar palacial em Israel Norte ${ }^{10}$ e em Judah, governantes originários do setor rural em cuja administração a alta tributação viabilizou projetos urbanísticos e construção de prédios oficiais. ${ }^{11}$

Naturalmente, a manifestação de independência de Amós não se restringe ao Estado, cabe também crítica às legitimações de poder oriundas dos grandes produtores rurais, isso - e

\footnotetext{
${ }^{8}$ Cf. Amós 7.10-17. Aqui cabe informar que os textos bíblicos são citados da BHS (cf. ELLIGER; RUDOLPH, 1997).

${ }^{9}$ Milton Schwantes refere-se a Amós 1.3-2.16; 3.3-4.3; 7.1-9; 7.10-17; 8.1-3; 9.1-4.

${ }^{10}$ Veja acerca disto a liderança do ruralista Jonadab, filho de Rekab, em apoio ao militar Jehu no sangrento golpe de Estado ocorrido em 842/841, em 2Reis 9-10.

${ }^{11}$ Apesar da idealização que se faz ao reino de Judah e seus reis na historiografia deuteronomística, podemos acessar evidências de que o processo de estatização das tribos teria sido iniciado por Davi, assim como as coletas para a construção de santuário e o recenseamento da população como medida de controle econômico (2Samuel 21Reis 2), além das coletas para construções dirigidas pelo rei Jeoash (835-796), em 2Reis 12, foram possibilitados pelas estruturas tributárias vigentes. Claro, a historicidade das escalas dos reis na Bíblia Hebraica requer revisão, mas inexistiria empreendimento urbanístico sem o aporte da tributação dos produtores do setor rural.
} REVISTA RELEGENS THRÉSKEIA - 2021 - UFPR 
não apenas a exigência em não ser vinculado aos profetas baseados nos templos oficiais e sua dependência econômica - pode ter sido um dos motivos para o dito "Eu não sou profeta e não

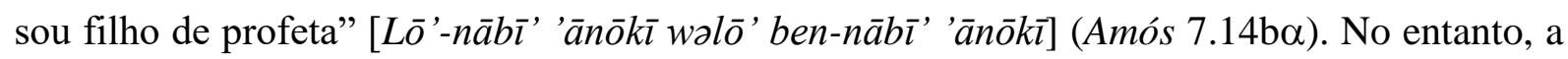
descoberta de que existem interesses no aumento de preço dos produtos com a anuência do rei, apesar de a relação representar uma rede comercial comumente praticada no Levante, faz com que esse seguimento da sociedade seja transformado em alvo do protesto, como Pixley havia percebido antes de mirar as relações estabelecidas no espaço sagrado. Talvez, a atração que o campo religioso exerceu sobre a sua interpretação historiográfica o tenha impedido de descobrir que o problema se situa na história do político, não na história da religião: Amós é líder de um protesto político organizado por importante parcela de produtores rurais que não participam da rede comercial liderada pela aristocracia econômica e política ligada ao rei. A instituição com representante do rei e da política comercial mais próxima de Teqoa (Təqôa ), cerca de dezessete quilômetros ao sul de Jerusalém, localiza-se em Betel (as duas outras opções seriam Samaria e Dan), em cuja representação designada pelo rei encontra-se o sacerdote Amaziah.

Desafortunadamente, não temos a resposta do rei ao receber o relatório do seu representante, mas lembramos que o rei Jeroboam II foi, depois dos reis da dinastia omrida, aquele que mais promoveu o desenvolvimento urbano de Israel Norte. Esse rei esteve envolvido em muitos conflitos com Aram-Damasco, ${ }^{12}$ controlou as cidades de Qarnaim (Qarnīnu), no sul de Damasco, e Lo-Debar, no vale do rio Yarmuk, e estendeu sua influência territorial de Hamat ao Wadi Arabah (cf. Amós 6.13-14; cf. YOUNGER, 2016, p. 641-42). Com certa razoabilidade, a pauta da reunião oficial pode ter sido sobre a conclusão das grandes construções palaciais e residências populares, o bem estabelecido comércio internacional que ligava Israel Norte ao Mediterrâneo (incluindo Tiro e Sidon na Fenícia) e a rotas que faziam a ligação entre a costa e a Anatólia, o necessário gasto com a defesa diante dos constantes avanços arameus de Damasco e, mais recente, o forte assédio do império neoassírio.

Buscar procedimentos políticos a partir do ponto de vista de um sacerdote ou profeta como se fora a "tradição do Javé" - dependendo da posição ideológica que se assume a "favor" do pobre ou fazendo uma translação religiosa -, numa exigência de fonte argumentativa, revelou-se um trabalho de curto alcance. No caso das camadas literárias do Livro de Amós, os

\footnotetext{
${ }^{12}$ Muitos acontecimentos e construções atribuídas na Bíblia Hebraica ao rei Salomão estão sendo revistos à luz das novas pesquisas históricas e arqueológicas, pois referem-se ao rei Jeroboam II, por exemplo: 1Reis 5.1 [4.21]; $8.65>2$ Reis 13-14 $(14.25,28)=$ Amós 6.13-14.
}

REVISTA RELEGENS THRÉSKEIA - 2021 - UFPR 
temas têm características de discursos ou panfletos, por vezes à maneira de lançamentos de dardos, depois compilados.

Onde a "tradição de Yahweh" apoia os discursos? Na associação daqueles homens e mulheres das categorias ligadas às administrações diretas do templo e do palácio aos agentes da rede comercial, fundando em Samaria o sistema templo-palácio. Aliás, nos Estados territoriais, pequenos e grandes reinos em que vige o sistema tributário, o templo deixa de funcionar como "central de arrecadação de excedente"13 e passa a funcionar como entreposto. O modelo de administração em parte compartilhada por anciãos e sacerdotes nos santuários de entidades políticas pré-estatais impede o cacique ou governante de deter todo o poder, mas nas entidades com estruturas reais a burocracia que ordena a administração da atividade tributária é a mesma seguida pelos sacerdotes nos templos e nada impede, portanto, que seus agentes palaciais frequentem o templo e ofereçam culto sacrificial e cânticos para a divindade, não obstante o vidente e seus seguidores considerarem isso um ato injurioso ou blasfemo contra Yahweh.

Nesse sentido, para interpretar as várias camadas literárias do capítulo 5 do livro, nenhuma pertencente à ipssissima vox Amos, como camada redacional de referência à acusação de corrupção do direito, seja oralmente traditada, seja como código cuja leitura em lugares forenses valida o processo, requer do leitor ou leitora antes escavar fontes que possibilitem compreender esta pequena coletânea como parte da redação dos capítulos 3-6. Nela, as profecias de desgraça dialogam destacadamente com uma lamentação pela destruição de Israel Norte, vítima das guarnições do império neoassírio. Ou seja, a base introdutória ${ }^{14}$ indica a redação post eventu das várias denúncias coligidas. Assim, o relatório acerca dos julgamentos fraudulentos nos fóruns locais (5.12b: "repelem os pobres ['ebyōnīm] no portão [bašš 'ar]"), apesar da grande importância social, perdeu espaço para as lições da moral religiosa e foi resumido a refrão (veja Amós 5.10, 12, 15). Schwantes (2013, p. 100-103) propõe resolver o projeto editorial do rolo ou livro fazendo conexões, portanto deslocando palavras a partir de sua significância para o contexto que passa a ser estabelecido.

A nosso ver, ficaria solucionado o problema se a interpretação admitisse a centralidade da política comercial e tributária regional, ou seja, buscar os precedentes históricos do objeto da acusação. Em torno da política estatal dirigida pelo rei funcionam as estruturas privada e

\footnotetext{
${ }^{13}$ Schwantes (2004, p. 200) pensava no uso do excedente da produção pelo templo em pleno Estado tributário!

${ }^{14}$ A base introdutória da narrativa é Amós 5.1; no entanto, a camada redacional 3-6 tem dois títulos, em Amós 3.1 e 5.1 . 
estatal; a essa última, encontra-se subordinado o sistema de justiça, cujos juízes condenam os endividados e miseráveis sem levar em conta as funções dessas mesmas estruturas - elas legitimam um sistema comercial desonesto e fraudulento. Operativamente, o sistema econômico recebe apoio do sistema judicial, arbitrariamente parcial e corrupto. Ao acrescentar na camada social em que se encontra o pobre ou escasseado ainda não miserável ('ebyōn) outras categorias do mesmo ambiente social, tais como o "fraco" (dal) e o oprimido ( 'ân $\bar{l})$, fica evidente que a corrupção não pode mais ser eliminada porque tornou-se inerente à entidade política. Por outro lado, a supressão de direitos ocorria em consequência da parcialidade dos agentes do sistema de justiça, cujo controle era exercido pelas elites dirigentes de Samaria, aliadas dos grandes comerciantes. O reino mantém uma justiça com códigos próprios que funcionam com viés circunstancialmente punitivista.

\section{Os contextos: contrapontos historicizantes}

Com a exigência de novas escalas científicas para que a Bíblia Hebraica seja encontrada em seu ambiente cultural, como obra do antigo Oriente-Próximo, a literatura retoma o seu lugar político. Recentemente, realizamos uma historiografia da política nesses contextos (cf. SANTOS, 2021), por isso a nossa tarefa aqui será fortemente epigráfica. O acontecimento está na linguagem, por isso a objetificação dos contextos apenas o distribui como uma sucessão de eventos. ${ }^{15}$ Nesse sentido, a reconstituição do acontecimento, distintivamente aos períodos e fronteiras políticas num Levante integrado ao mundo Mediterrâneo, mostrará que tanto o Levante quanto o Mediterrâneo estão repletos das culturas siro-mesopotâmias no primeiro milênio.

Nessa linha, suscita particular interesse a criação da estrutura imperial da Assíria. Na primeira metade do século VIII a Assíria passava por crise interna, os governantes de cidadesEstado nos entornos dos rios Tigre e Eufrates mantinham certa independência não obstante a relação provincial com o império. A crise iniciada nas primeiras décadas do século VIII teria sido motivada pelo fato de os reis assírios demonstrarem imperícia militar (MIEROOP, 2020, p. 323). As funções da sociedade atestam que entre os séculos IX e VIII houve um enfraquecimento das estruturas palaciais. Esta situação mudou internamente na segunda metade do século VIII quando Tiglat-pileser III e depois dele, Sargon II (721-705), suprimiram poderes das autoridades que se reportavam diretamente ao rei. Então, passou-se a nomear eunucos

\footnotetext{
15 Acerca disto, visando a elaboração de exegese contextualmente histórica em relação ao campo religioso do antigo Israel, recentemente foi publicada uma pesquisa de teoria e metodologia; cf. SANTOS, 2019 a.

REVISTARELEGENS THRÉSKEIA - 2021 - UFPR
} 
visando impossibilitar a transferência de autoridade ou sucessão familial de cargos públicos e aumentou de um para dois o número de comandantes do exército, como tentativa de diminuir o poder dos oficiais militares. Externamente, como documentado por Marc van de Mieroop (2020, p. 323), fora mudada a divisão territorial das províncias, cujo controle das decisões locais saiu em grande parte das mãos dos governantes designados para ficar centralizado no rei.

O processo de tributação e expansão territorial foi bem sucedido porque a organização das campanhas no sul do Levante obedeceu um planejamento segmentado, considerando perspectivamente novos inimigos como Hamat e antigos inimigos como Damasco, deixando em segundo plano político o reino de Israel Norte, reino que seguia perdendo importância econômica e territorial para o reino unido de Aram-Damasco, e sem mirar os pequenos reinos

Figura 1. Mapa do império neoassírio

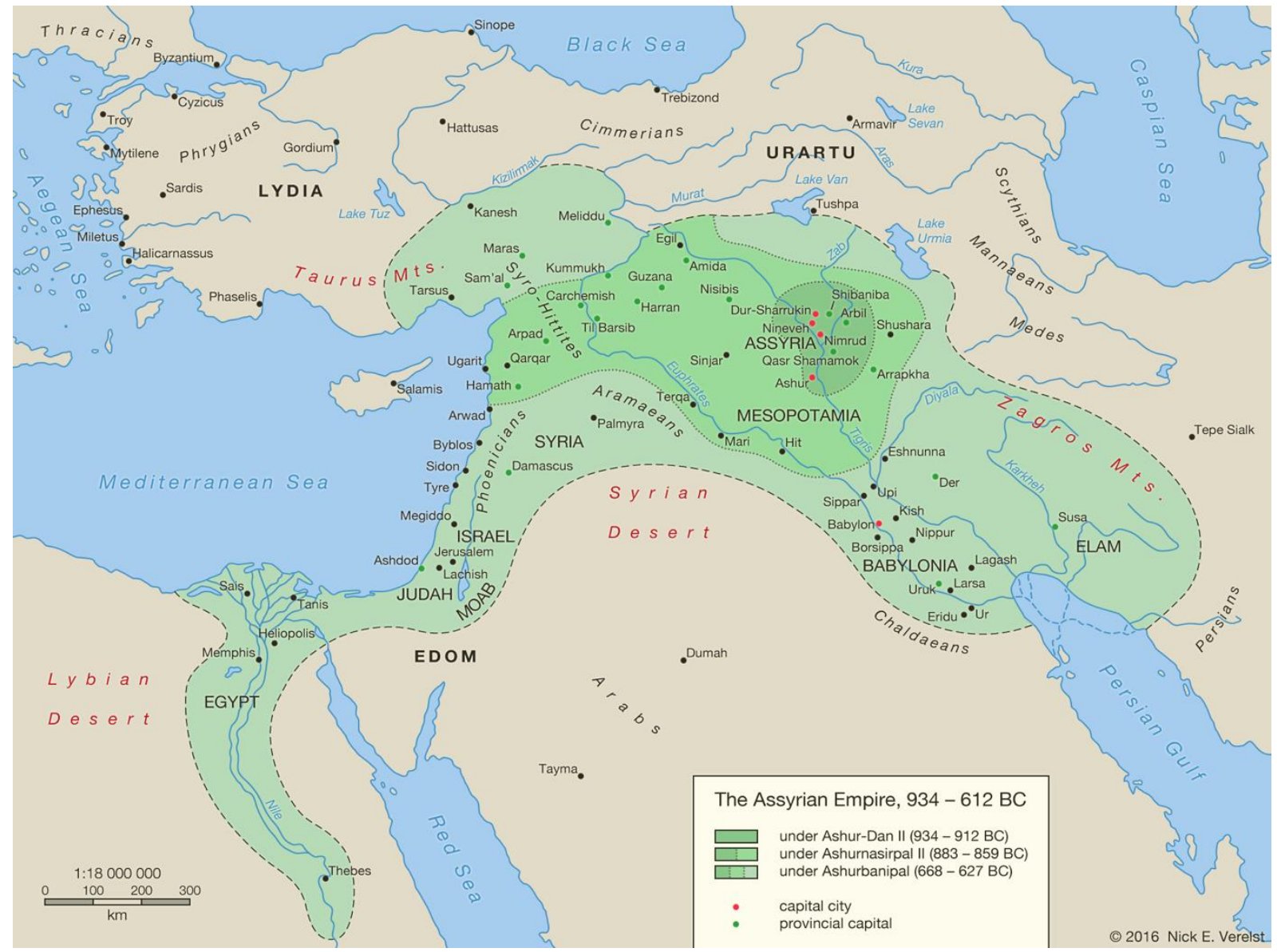

Fonte: DevianArt.com/undevicesimus (Acesso livre) 
por sequer fazerem parte das bordas imperiais (p.ex., Moab, Edom e Judah), mas também por não ameaçarem com qualquer gesto que representasse uma nova coalizão regional antiassíria. ${ }^{16}$

Tiglat-pileser III reduziu Israel Norte aos territórios de Efraim e Manassés, posteriormente fez reinar a Oseas (732-724) como vassalo e constituiu o restante do reino nas “províncias assírias de Dor (na costa até o Carmelo), Megido [Megiddo] (a Galileia) e Gile“ad (a leste do Jordão)", além de deportar 13.520 israelitas (LIVERANI, 2008, p. 187), talvez ainda não inteiramente numa deportação cruzada.

A situação não levou Israel Norte a abandonar as suas antigas posições antiimperialistas; logo após a morte de Tiglat-pileser III, o rei Oseas, valendo-se da liberdade que lhe proporcionava a lealdade, deixou de pagar tributo. Em represália, Shalmanasar V (726722), que vinha de intervir em cidades da Fenícia e cercar o território israelita por três anos, pouco antes de morrer invadiu a capital de Samaria. A autoria da conquista militar que transformou Samaria em província foi disputada por seu sucessor Sargon II; como os anais foram elaborados após a morte de Shalmanasar V, o documento assírio designa a autoria da conquista ao seu sucessor.

Este detalhe histórico talvez seja o responsável por Pixley enunciar em sua História que "no ano de 722, sendo rei Sargão II, a cidade de Samaria foi capturada". A invasão comandada por Shalmanasar V em 722 foi enunciada nos anais dirigidos por seu sucessor, Sargon II, por meio do qual sabe-se que "27.290 dos seus habitantes [samaritanos]" foram deportados e levados 50 carros de guerra das guarnições de Israel Norte (LIVERANI, 2008, p. 189; MIEROOP, 2020, p. 325-27). Agora sim, uma deportação inteiramente cruzada.

A tributação de bens, como chave histórica para compreender o empobrecimento da parcela da população que nem era beneficiada por suprimento nem fazia parte das categorias da administração direta do templo ou do palácio, aproxima-se de significações redutoras daquelas sociedades complexas. De outra forma, na linha da afixação de oralidades, as lembranças de êxodos populacionais (cf. Amós 2.10; 3.1-2; 9.7), preservadas no setor rural, aglutinaram agricultores e pastoralistas sob a liderança de Amós. Na verdade, Amós é um nōqēd - "pastor" criador de gado miúdo - que vive entre ou representa os nōqdìm (cf. Amós 1.1a). Nossa hipótese é que as profecias, nas quais “Amós” denota o escriba, em suas várias etapas de atualização e redação, representam reivindicações de médios e grandes agricultores excluídos de rede comercial, contrários ao sistema de tributação e ao aumento do preço das mercadorias.

\footnotetext{
${ }^{16}$ Aludimos à coalizão antiassíria liderada por Hamat, Damasco e Israel Norte contra o rei Shalmanasar III nos anos 853, 848 e 845, cujo primeiro conflito aconteceu na cidade de Qarqar. 
Na busca da comprovação da nossa hipótese, a mudança do plano de fundo nos permitirá o nosso acesso a essa realidade externa.

Os movimentos temporais marcados nos sobrescritos dos livros da Bíblia Hebraica não nos lançam suficientemente nem aos eventos nem à mentalidade dos narradores, mas isso não torna pouco importante a investigação acerca da visão de mundo de cada narrador identificado. Ou seja, na literatura profética e historiográfica os meios conceptuais em que se orientam os agentes envolvidos revelam quais significações e objetivos serão deslocados ou inventados; visa-se o estabelecimento de uma realidade que se desejava concreta para a audiência. No caso dos anais reais e dos dados fornecidos pela profecia, a descrição da geografia mapográfica revela mais do que os limites de cidades e as novas bordas imperiais porque nos assegura o acesso aos contextos.

Cécile Michel (2014, p. 245; veja também: SANTOS, 2019a) demonstra que a visão de mundo dos reis mesopotâmios modifica-se à medida em eles exploram regiões longínquas em suas campanhas militares; no entanto, a geografia "mistura o real e o fantástico e parece ter sido feito a partir de relatos de viajantes e da literatura mítica”. Com relação ao antigo Israel, juntamente com a geografia acrescentamos as narrativas de conquista e as profecias que passam a fazer parte dos lugares enquanto circunstancialidade da vida da população. Por essas construções linguísticas passa a mentalidade, numa premissa ontológica na qual o mundo com seus acidentes e exílios merece atenção por ser imanente a Yahweh. A evolução dessa mentalidade acaba por operar a individuação de um protesto futuro contra os malfeitos de líderes do poder historicamente estabelecido.

Evitar anacronismo é muito difícil. Com efeito, lembrou-nos Sahlins (cf. 2019, p. 21) que todo pensée sauvage ("pensamento selvagem", expressão consagrada por Claude LéviStrauss) exige "uma reflexão sistemática, intensiva e imaginativa sobre a experiência, sobre as propriedades e relações das coisas", sendo as experiências diferentes de lugar a lugar. Diante da biblioteca bíblica, seria razoável tomar as distinções a sério.

Se as culturas - evitemos a singularização do que expressa o termo "civilização" - são o que identifica determinado povo será por meio delas que o grupo social se organiza, então para a sua interpretação torna-se imprescindível a disposição empírica sugerida por Sahlins (2019, p. 21, 29), pois "não se pode fazer uma história de qualidade, nem mesmo história contemporânea, sem respeito às ideias, ações e ontologias que não são e nunca foram as nossas próprias". As diferenças destacam-se no senso prático aplicado quando fica clara a experiência constituída pelo acontecimento (conjunto de eventos), ou pela tradição e memórias, 
transformador a ser interpretada com base num critério de objetividade etnográfica, sabendo-se que a experiência memorial é resultado de saberes locais que perspectivamente indicam identidade social diferenciada.

De acordo com isto, o documento, mesmo tendo adquirido uma função constitutiva e transformado em monumento da sociedade, permanece sendo uma porta de acesso, fornecedora de base proveitosa para se inferir conclusões. Mas como ensinou Sahlins a Gananath Obeyesekere (cf. 2019, p. 191), "as coisas são conhecidas pelas suas relações com um sistema de conhecimento local, não simplesmente pelas suas relações objetivas" porque "a ‘objetividade' é culturalmente constituída”, assim como o saber coloquial oriental.

Deste modo, ao conectarmos as fontes aramaicas ao Israel Norte ficam visíveis, no quadro político do Levante, os israelitas e as pactuações políticas denunciadas em linguagem elíptica por Amós, própria da concisão dos panfletos. Por exemplo, a composição do oráculo contra Damasco (Amós 1.3-4, 5) revela um vidente capaz de indicar com segurança Bêt 'Eden, uma pequena cidade em dimensão territorial e em importância econômica mas que participa do contexto de conflito no qual fazem parte os israelitas. Essa cidade síria tem sido identificada como Bit-Adini (Bīt-Adīni), localizada entre o Alto Eufrates e o rio Balih (Balīh $)$ em província assíria conquistada por Shalmanasar III no ano de 855. Um envolvente debate em torno dessa cidade mencionada por Amós foi estabelecido por K. Lawson Younger (2016, p. 366-71). Afora o problema de definição geográfica, isso nos leva a pressupor que o vidente descobriu, a partir de sua compreensão conjuntural, que estava em curso uma coalizão contra Israel Norte liderada por Rezin ou Raḍān (c. 750-732) do reino unido de Aram-Damasco e Shamshi-ilu de BitAdini, representante assírio na região.

A conjuntura é entendida a partir das informações transmitidas pelas culturas de mobilidade, elas mantêm na memória as migrações aramaicas; ligando as formas de vida, os discípulos do vidente compararam as experiências. Uma forma estranha de comparação entre diferentes socioetnias e ações libertadoras destina-se à exaltação de Yahweh: integra-se a migração de israelitas do Egito, dos pelishtim de Kaftor e dos arameus de Qir. ${ }^{17}$ Temos aqui uma geografia do Levante: a faixa central e parte do lado leste do rio Jordão, o lado oeste ou as populações da costa do Levante e a grande região do norte da Síria próximo a Emar, no Alto Eufrates. Apesar de o acontecimento ter desaparecido dos anais de Tiglat-pileser III, pesquisas confirmam que em 732 esse rei capturou moradores de Damasco e deportou para Qir

\footnotetext{
${ }^{17}$ Cf. Amós 9.7. Na pesquisa de fontes sobre Qir, Younger (2016, p. 41, n. 38) sugere que a referência de 2Reis 16.9 é citação tomada de Amos 1.5 e 9.7 . 
(YOUNGER, 2016, p. 41). Pela lonjura geográfica em que se encontra o escriba do panfleto, possivelmente o registro comparativo no livro se refira a elementos linguísticos preservados da cidade de Qir, mas referindo-se a Damasco.

Embora com motivos teológicos e retroprojetados, a memória do êxodo do Egito e dos assentamentos na terra de Canaan, mas também a ideia de deslocamento de soberania política, serve ao processo contra os israelitas. Mario Liverani (2008, p. 339-43) nota que o enunciado em Amós 9.7b, em nossa tradução literal "Não a Israel fiz subir da terra do Egito, e os pelishtim de Kaftor e Aram, de Qir?”, é uma formulação migratória, muito embora sirva como “metáfora de libertação do domínio estrangeiro". Situa-se, portanto, na historiografia protodeuteronomística do século VII com indícios no livro; está presente nas memórias dos seguidores de Amós a política assíria de deportações cruzadas praticada sistematicamente no século VIII, nelas povos subjugados são lançados a rotas migratórias.

Para além disso, uma inscrição do rei Shuppiluliuma I (c. 1344-1322), fundador da primeira dinastia do Reino Novo hitita, apresenta o que Liverani chama de "código motor", entradas e saídas de povos com a qual o enunciado profético se assemelha: "A cidade de Qatna com todos os seus bens, eu os fiz entrar na terra de Khatti [Hatti]... Num só ano eu tomei e fiz entrar todas essas terras nas terras de Khatti [Hatti]" (LIVERANI, 2008, p. 340; cf. MIEROOP, 2020, p. 211-15). No caso do enunciado profético, reflete-se metaforicamente entradas e saídas do Egito tendo a Yahweh como aquele que promoveu os assentamentos fundantes de vários povos, fornecendo elementos interpretativos para inserir outro processo, a saber, culpa e punição a Israel Norte.

De várias maneiras, as relações internas e externas da época do reinado de Jeroboam II são tomadas como base para os enunciados dos protestos inicialmente liderados por Amós, mesmo que a ideologia de libertação descolada da tradição do êxodo, como entendeu Rainer Kessler (2010, p. 128), seja lembrada como algo a ser superado diante da realidade vivida.

\section{Os contextos: materialidade histórica para estudo interpretativo}

Embora os conteúdos do livro e a figura do vidente continuem como fontes de interesse para estudiosos, muito em função do fascínio que exercem em relação aos importantes temas sociais do tempo presente, as interpretações apresentam invariavelmente um projeto ideológico. Destarte, o problema que mantém reduzido o conhecimento histórico acerca do vidente consiste em que "a maioria da documentação acha-se concentrada em duas passagens (Am 1,1; 7,1017), mas também pelo fato de que o livro demonstra ter tido longa e complexa história de 
transmissão" (WILSON, 1993, p. 242). Nesse sentido, a ideologia incorre em anacronismos especulativos pela impossibilidade de se confirmar uma reconstituição historicamente descritiva do vidente e suas atividades. Isto seria apenas uma crítica se as camadas literárias que formam o núcleo do livro não fossem resultado de muita labuta editorial que durou cerca de quatro séculos. Em relação ao conjunto redacional canônico que temos à mão, será preciso multiplicar as copiações, adições, revisões e editorações cujos agentes e épocas podem ser localizados até no século III, no contexto das tradições legais rabínicas. ${ }^{18}$

A coletânea de visões (Amós 7-9) tem sido considerada como trabalho interpretativo do período persa; assim interpreta Konrad Schmid (2013, p. 209, 223-25), que inclui ainda a reelaboração de profecia orientada pela formação da Torah para responder ao por quê da queda de Judah. A pesquisa sobre as escriturações revelou quatro camadas literárias sobre o que seria a ipssissima vox Amos. A reconstrução lítero-teológica apresentada em detalhes por Schwantes (2004, p. 142), seguindo as descobertas do seu professor Hans Walter Wolff, indicam manuscritos da "antiga escola de Amós", ${ }^{19}$ uma "interpretação de Betel", 20 "a redação deuteronomística" 21 e a pós-exílica "escatologia de salvação", 22 demonstrando, assim, o longo curso espaço-temporal das memórias e tradições em torno do vidente.

Ironicamente, muitos profetas recusariam peremptoriamente o título pelo qual se tornaram conhecidos, "profeta” (nābī'). Segundo os debates atuais, esses indivíduos não se identificavam como "profetas" e poderiam ser mesmo "poetas" ou intelectuais defensores de causas sociais. Há quem veja no Livro de Amós semelhanças com fragmentos de lamentos de Sumer por destruição de cidades e com profecias também da Mesopotâmia da época do império neoassírio (cf. MILSTEIN, 2013). O livro então representaria uma obra compósita editada por poetas que teriam, no trabalho de escrituração, compilação e redação, acrescentado seus comentários teológicos e crítica social designando-os como "profecias", e entregue em forma de profecia aos judaítas e refugiados israelitas após a queda de Israel Norte (MILSTEIN, 2013, p. 442-43). É possível notar que, entre os séculos VIII e VII, os gêneros da literatura também têm a intenção de monumentalizar a experiência religiosa; p.ex., a visão dos céus e o grandioso encontro com Yahweh em Isaías 6. Com relação a isso:

\footnotetext{
${ }^{18}$ Veja sobre as tradições literárias no período persa em: SCHMID, 2013, p. 187-225.

${ }^{19}$ Amós 5.13, 14-15; 6.2, 6b; 7.9, 10-17; 8.3, 4-7, 8, 9-10, 13-14; 9.7-8, 9-19; partes de 1.1; 5.5 e eventualmente de $2.10-12 ; 5.25-26$. "Essa escola teria atuado em torno de 735, em Judá".

${ }^{20}$ Amós 1.2; 4.6-12, 13; 5.6, 8-9; 9.5-6; parte de 3.14. "Essa releitura teria ocorrido na área do santuário de Betel, na época de Josias (no terceiro quartel do século VII)".

${ }^{21}$ Amós 1.9-10, 11-12; 2.4-5, 10-12; 3.7; 5.25-26; parte de $1.1 ; 3.1$ e eventualmente 8.11-12. Os redatores dessa redação deuteronomística "teriam atuado, na Palestina, na época do exílio".

${ }^{22}$ Amós 9.11-15; partes de 5.22; 6.5. Redação do período posterior ao exílio babilônio. 
Em Amós 3.3-8, a ênfase estava, em vez disso, no impacto de tal encontro no indivíduo. Neste caso, os detalhes do encontro foram menos importantes do que a sensação de compulsão que procedeu do encontro. Em vez de narrativa, o relato assumiu a forma de uma série de charadas dirigidas a um público. Nenhum dos textos teria procedido de um paradigma ou tipo definido, embora a chamada de Isaías viesse a formar o protótipo para imitações posteriores. A situação de Amós 3.3-8 na frente de 3.9-6.14 então lança todo este bloco de material como "profecia". Isso é verdade se o relato de chamada foi redigido pelo escriba responsável por 3.9-6.14 ou se a chamada deve ser atribuída a uma mão diferente. É importante notar que o relato de chamada em Amós é o único discurso de primeira pessoa atribuído ao profeta em todos os capítulos 3-6. Além disso, não há uma única referência a "Amós", apenas a insistência na compulsão do falante de profetizar. (MILSTEIN, 2013, p. 444 - trad. nossa).

A camada redacional de 3-6 exemplifica os casos de independência de manuscritos e de autoria constatados no livro, nos quais não se tem em vista enunciados subordinados à autoridade literária de Amós, a ausência do aporte autoral no núcleo destacado da redação o indica e separa do cabeçalho redacional de Amós 1.1. Neste e noutros casos, "Amós" denota o escriba.

A partir da compreensão aprofundada dos contextos é possível realizar uma mínima reconstrução da iconografia literária do vidente; consequentemente, interessa-nos elaborar uma nova perspectiva para a recepção de Amós e do livro, sua linguagem e cenografia. Martti Nissinen propõe tematizar os templos como locais de apresentações ou encenações proféticas:

O caso mais revelador é, sem dúvida, Amós confrontando o sacerdote Amaziah no templo real de Betel (Amós 7.10-17). Embora negue veementemente que seja um "profeta ou filho de profeta", isso é o que Amós é em todos os aspectos com relação ao local e ao conteúdo de sua proclamação. O cenário é em muitos aspectos comparável às encenações de Jeremias no templo de Jerusalém, incluindo a origem posterior de Amós do texto e o papel do sacerdote como administrador - novamente, um modelo bem conhecido no meio cultural do Oriente Próximo. (2017, p. 245 - trad. nossa).

Há uma tradição de longa duração que respalda o cenário para o embate em torno do protesto social - usado antes de diferentes formas por Ahiah (1Reis 11.29-39), Isaías (Isaías 6) e Jeremias (Jeremias 7.1-15; 26.1-19; 29.26-27). Simultaneamente a isto, o local qualifica o agente da denúncia e as redações do livro vão suprimindo alternativas para a fixação de uma teologia de dupla entrada e saída para intervenções exegéticas. Mas sempre restará a mística, ao final!

A mística da atividade intelectual ideologicamente favorável ao pobre conectou um emblema em grupos sociais escravizados ou escasseados por socioetnias mais potentes, incluindo necessariamente o pequeno produtor do setor rural e o pequeno comerciante citadino. 
Schwantes (2008, p. 40) afirma que "o povo era ainda mais pobre, como mostram os profetas do século [VIII], a exemplo de Amós que, em 760 a.C., é anterior à expansão assíria”. Ora, Kessler (2010, p. 141) lembra que o livro não trata acerca de pessoas miseráveis e que sequer menciona viúvas e órfãos, trata de categorias que ainda produzem no setor rural e comerciantes citadinos. Sobre isto, temos evidenciado a condição social privilegiada de Amós e os pastoralistas proprietários (cf. SANTOS, 2021).

Nossas revisões consideram sobretudo o fato de que o livro indica sua vocação historicizante ao enunciar o terremoto (cf. Amós $1.1 ; 2.13$; 9.1) como marco cronológico definidor. Primeiro, as bases da expansão da Assíria foram colocadas no século IX, nos reinados de Assurnasirpal II (883-859) e Shalmanasar III (MIEROOP, 2020, p. 314). A guerra de Qarqar, ocorrida em 853, marca definitivamente a presença da Assíria no Levante e em 841, o Obelisco Negro, anais em forma de relevo e documento literário de Shalmanasar III, reproduz em quatro relevos a submissão do rei israelita Jehu e o carregamento de tributos destinados ao rei assírio. Segundo, é pouco provável que Amós represente efetivamente as lutas dos pobres e miseráveis: as camadas literárias que tratam do tema não são ipssissima vox Amos, ou seja, sequer podemos pressupor experiência ou visão de mundo do vidente mas de seus seguidores, e a sua condição social o coloca na categoria de elite do setor rural - fruticultor de espécies importadas e fazendeiro de gado miúdo. ${ }^{23}$

Com efeito, o protesto deve-se à alta dos tributos, mecanismo de controle do circuito comercial que sempre existiu em sociedades estatais. Em síntese, o encarecimento dos produtos e sua revenda comercial leva tanto o produtor quanto o comerciante à impossibilidade de repor os meios de produção (sementes, ferramentas, animais, pagamento de mão de obra); ato contínuo, ocorrem o prejuízo econômico, o endividamento, a dependência de credor, a perda de propriedade e a situação ou estado de pobreza que gera a escravidão e a morte.

A capacidade econômica requerida pela atividade exercida por Amós por meio da criação de gado miúdo (ovelhas, cabras etc.) e do cultivo de figos importados dos entornos do mar Morto e da Sefelah responde a que se destina o seu protesto. Na própria descrição de objetos de luxo se descarta qualquer indício especulativo por parte de quem os apresenta; além disso, a paisagem arquitetônica da cidade de Samaria com o mais importante palácio do Levante não é descrita como por cartão postal, mas por quem já visitou a cidade.

\footnotetext{
${ }^{23}$ Veja a autoidentificação do "vidente" como criador de gado e fruticultor (vaqueiro: bōqēr; figueiras: šiqmīm; gado de pequeno porte: ș'ōn) em Amós 7.14bß,15a.

REVISTA RELEGENS THRÉSKEIA - 2021 - UFPR
} 
No todo, fica evidente a condição social de Amós e ressalta que o que tem sido interpretado como “ameaça às elites” de Samaria (Amós 3.9-4.3) é, na verdade, protesto político contra a administração estatal que foi elevada a potência pela dinastia omrida um século atrás; a estrutura administrativa é a responsável por colocar a capital no mesmo nível de importância política de Damasco e Hamat. O protesto visa também a acelerada urbanização das cidades. Esses empreendimentos tecnológicos e de urbanização geraram aristocracias que "amontoam violência e injustiça"; por outras palavras: os objetos de luxo, móveis e imóveis, foram adquiridos pela exploração econômica patrocinada pelo Estado, e o escândalo se completa com festas extravagantes nessas casas de pedra cortada e de madeiras nobres (cf. Amós 3.15; 6.3-4a, $4 b, 6 a)$.

A sequência da paisagem arquitetônica das casas luxuosas no enunciado de Amós 3.15, a saber, "marfim", “ébano" e "pedras cortadas" tem testemunho nas peças de mobiliário descritas em documentos de Ugarit, na costa do Levante, e do Egito (DIJKSTRA, 2016, p. 178). Disso depreendemos que se Ugarit importava esses materiais da África, as elites israelitas também os importavam, assim como a contratação de técnicos estrangeiros para a fabricação dos imóveis e de obras de arte decorativas e utensílios para as suas casas. Meindert Dijkstra (cf. 2016, p. 179-80, 193) menciona os painéis dos templos e palácios de Jerusalém e Samaria fabricados com cedro importado da Fenícia e as camas de marfim decoradas em estilo damasceno. Estão no alvo as pessoas das mais altas camadas sociais, ruralistas e citadinos privilegiados pelos empreendimentos estatais em curso desde o século IX (cf. 1Reis 22.39).

Em termos históricos, as políticas funcionam como uma espécie de poder seletivo, onde apenas os membros das categorias ligadas à administração direta do templo e do palácio não têm motivos para protestar. É provável que a atitude requerida das elites seja a divisão solidária do excedente, utopia nunca praticada em qualquer época. 
Outro problema a ser equacionado com o auxílio das novas descobertas do período neoassírio diz respeito à escrituração como fenômeno cultural no interior dos movimentos proféticos israelitas. Os profetas representam grupos sociais, contam-se também os discípulos, que se abrem por primeiro à difusão de manuscritos e sua atualização. Caso o motivo para a composição literária tenha sido o impacto social das mensagens transmitidas, pode-se realmente entender as camadas redacionais como interpretativas. Critério diferente lograram os redatores do período posterior ao exílio babilônio, pois buscavam amenizar a profecia de desgraça

Figura 2. Mapa da anexação assíria dos Estados semíticos ocidentais no século VIII

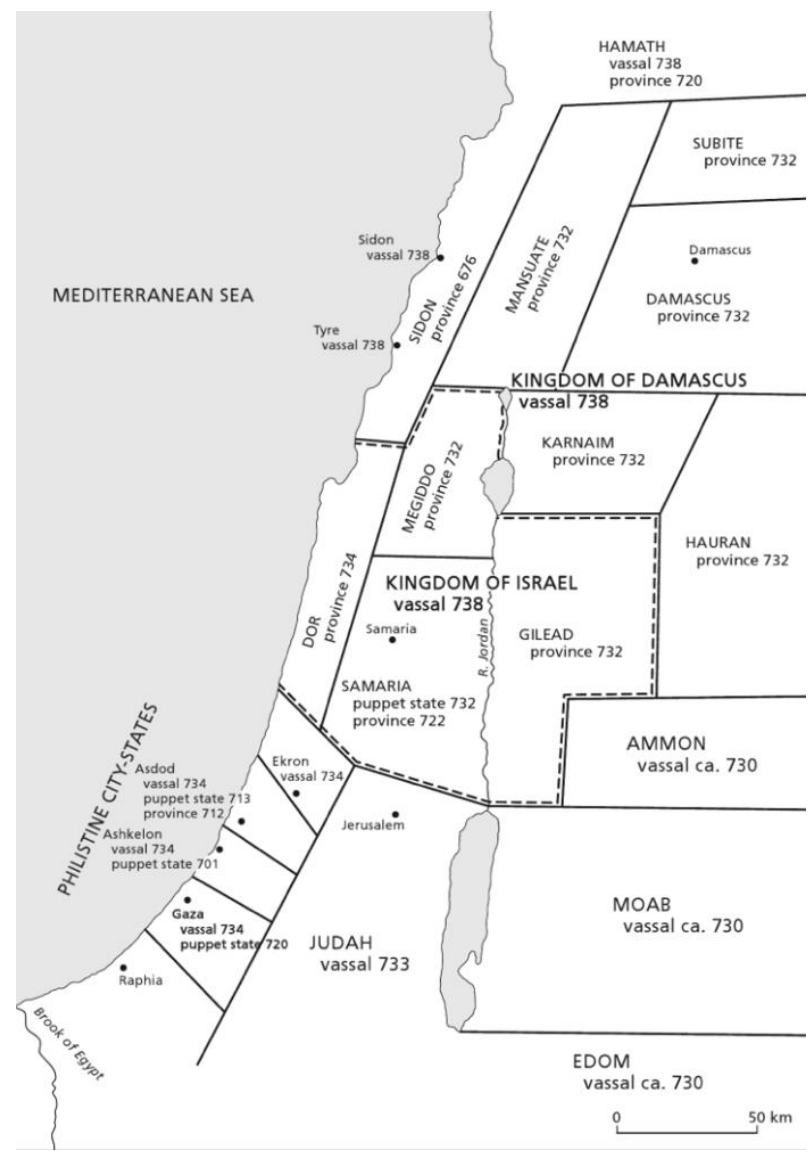

Fonte: MIEROOP, 2016, p. 269.

elaborada como protesto contra o sistema tributário e os privilégios concedidos às elites urbanas, acrescentando uma palavra de reconstrução futura formulada em chave davídico- 
messiânica (veja em Amós 9.11-15 a esperança pela restauração do Estado tributário!) e logo adequando os manuscritos às exigências litúrgicas do assim chamado Segundo Templo. ${ }^{24}$

A introdução de uma interpretação que avançasse à compreensão de que as entidades políticas deveriam ser conservadas, inclusive por grupos situados no setor rural contrários ao seu processo de desenvolvimento político-econômica, seria refutada por biblistas inovadores e tradicionais. Entretanto, o rompimento com tradições estatais representado pelos movimentos operados pelos profetas do século VIII nunca significou necessariamente apoio aos invasores. As destruições e exílios impostos a Israel Norte e a Judah, respectivamente pelos impérios neoassírio e neobabilônio, não são louvados; essas catástrofes são explanadas ou, por perspectivas teológicas evidentemente ambientadas em cenários religiosos, justificadas à luz do monoteísmo judaico.

Os cenários retrospectivos têm a função de contrapor-se ao tempo histórico no qual as categorias sociais estão em conflito. "Os edifícios são esplêndidos e luxuosos. Aumentam os recursos econômicos e agrícolas. Floresciam a indústria têxtil e a da tinturaria. Enfim, o reino de Israel encontrava-se melhor do que nunca"; no entanto, "a aliança com Deus converteu-se em letra morta, era recordada durante as celebrações litúrgicas, mas sem a mínima influência na vida cotidiana" (ALONSO SCHÖKEL; SICRE DÍAZ, 1991, p. 982). Difícil deixar de relacionar esse novo cenário no qual se testemunha o desenvolvimento urbano e os gastos militares com a alta tributação imposta aos produtores e comerciantes, pois são eles que, diante do empobrecimento em escalas de gravidade, organizam os protestos.

Todo esse cenário influencia o quadro político interno, mas desconsiderar os fragmentos da historiografia deuteronomística de Israel Norte, que são de uma época anterior à teologia da aliança, para sobrepor as tradições de tendência sacerdotal serve à apologia do profeta que se tem em mente. Considerar que tradições e memórias sociais reelaboradas liturgicamente estão mortas por causa da estratificação social é redutor dos problemas daquelas sociedades e as mantém submersas ao ambiente religioso. Afora as divinações praticadas nas cortes, a prática cúltica tem mais relação com costume familial e menos com a busca de segurança desde os seus inícios quando se tinha por intensão o presentismo da memória do parente morto (cf. SANTOS, 2018). Em termos conceptuais, será preciso inserir o Israel Norte como parte da articulação da história cultural do antigo Oriente-Próximo, assim como a Bíblia Hebraica. Considerando as

\footnotetext{
${ }^{24}$ Schwantes (2004, p. 100-101) menciona os refrães litúrgicos de Amós 4.13; 5.8-9; 9.5-6, mas ele pressupõe a organização do "livreto" antes da queda de Samaria em 722. Entendemos que o livro, com as composições litúrgicas e a palavra de esperança conclusiva, tem redação pós-sacerdotal realizada por volta do século IV. REVISTA RELEGENS THRÉSKEIA - 2021 - UFPR
} 
novas releituras do Livro de Amós, o crescente desejo de repensar os processos excludentes influenciado pela repulsa à política dos impérios neoassírio e neobabilônio resulta numa mensagem em que o ponto de vista da teologia de Jerusalém passa a reconstruir uma outra "realidade" para Israel Norte.

Considerando ainda o aspecto da influência dos escribas sobre a população, Schmid (2018, p. 487) postula que "a culturalização do poder persa tinha uma orientação substancialmente mais pluralista e aberta para a autonomia local do que, mutatis mutandis, a propaganda assíria tinha previsto". O fato de a política persa agradar a Judah diz muito acerca da sua influência nas tomadas de posição políticas que emergem nas teologias pós-sacerdotais, nas quais a restauração passa a incluir todos os israelitas, compreendendo as culturas israelitas como identidade materializada pelas concepções apreendidas nas interações culturais sirocanaanitas.

O protesto profético se descola do ambiente histórico-lendário dos patriarcas como designações de entidades políticas israelitas para indicar a relevância do lugar de fala do vidente. Enquanto "José" (Amós 6.6) indica a área central da terra de Canaan pertencente a Israel Norte, no centro do conflito menciona-se na parcela de destruição dos espaços sagrados de "Isaque" (Amos 7.9a: "E serão devastadas as bāmôt de Isaque e os santuários de Israel serão desolados"). Assim, no contexto literário do conflito com o sacerdote Amaziah, "Isaque" diz respeito às terras (Beersheba e Gerara) pertencentes a Judah, local de origem de Amós.

Mesmo que estejamos diante de estágio tardio para a distinção de preeminência da linhagem de parentesco mítica em que Abraham e Isaque são colocados sobre "Jacob-JoséEfraim-Israel", ${ }^{25}$ a profecia que critica Israel Norte acaba por denunciar Judah, o local de pertença do vidente. ${ }^{26} \mathrm{O}$ fato de a recepção da profecia chegar em Judah reelaborada à luz da indesejável queda de Israel Norte em 722, quando os seguidores do vidente tiveram-na por verídica, não implica em sua historicidade. Isso é mais uma atestação de que a crítica acerca da "letra morta" e da "opressão ao pobre" teria que começar em Judah.

A pesquisa literária do título de Amós como nōqēd, termo usado em muitas fontes acádios, auxiliou o aprofundamento das buscas por Amós. O nōqēd "aparece em listas de pessoal do culto e da política" (WILSON, 1993, p. 244). É difícil dizer acerca da ligação

\footnotetext{
${ }^{25}$ Para uma aproximação a esta perspectiva veja: SCHMID, 2013, p. 116-17.

${ }^{26}$ Afora a escrita da história do antigo Israel como parte do processo civilizatório do antigo Oriente-Próximo desde a Idade do Ferro I, particularmente a materialidade da história multicultural e política do Levante, este é mais um dos detalhes históricos que ainda não eram alcançados nem pela exegese bíblica de Alonso Schökel e Sicre Díaz nem, em parte, pelas análises de Schwantes.
} 
institucional, política e religiosa daquele judaíta que conhece diversas práticas cultuais de tradição javista (cf. Amós 5.21-23), fenícia e aramaica (cf. Amós 8.14). Jonathan Greer (2017, p. 13) sugere que o "profeta" ao mencionar esses cultos nacionais do norte "fornece todas as indicações de que eles eram javistas, mesmo 'ortodoxos' na prática”. A situação na qual as religiões são apresentadas indica mutação do culto do deus hitita-arameu Haddu. Não obstante, Amós é um membro das camadas economicamente altas de Judah que, como concluiu Robert R. Wilson (1993, p. 245), "tentou reformar os sistemas social e religioso segundo linhas judaítas".

A crítica às celebrações cúlticas como são encenadas e aos templos (Betel, Gilgal, Beersheba, Samaria, Dan, santuários em "lugares altos de Isaque" e "santuários de Israel") 27 parece ajuizar o fim da religião com todo o povo israelita. No entanto, tal ideia deve ser descartada por incorrer em subjetividade; se o objeto é culturalmente constituído, ${ }^{28}$ as experiências religiosas demonstram que as culturas são identitárias e isto as fundamenta. ${ }^{29}$ Caso particular de interação cultural envolvendo administração política e práticas religiosas de diversas etnografias pode ser encontrado em Dan (Tēl Dān; Tall al-Qậ̂̉). Dan tem recebido assentamentos desde o final da primeira metade do terceiro milênio; no século IX, tornou-se motivo de conflitos entre arameus do reino unido de Aram-Damasco e israelitas, cuja fonte artefatual, a "estela de Tel Dan", narra a disputa (SANTOS, 2019b). Ao mencionar Amós 8.14, onde emerge a imagem de uma divindade não nomeada venerada em Dan, Wolfgang Zwickel (2020, p. 132) afirma que a cidade foi conquistada dos arameus por Jeroboam II e anexada a Israel Norte, sendo provável que tenha sido posteriormente destruída pelo rei Tiglat-pileser III. Evidentemente, as práticas cúlticas que os seguidores judaítas e judeus de Amós arrolam às denúncias contra Israel Norte são milenares e apenas a preservação de tradição familial ancestral diz respeito em parte aos seus contemporâneos.

Em adição, assim como a supressão do culto a Yahweh, numa evidente translabilidade, não faz parte do projeto de produtores e comerciantes, também estão fora das profecias de desgraça o extermínio da população citadina ${ }^{30}$ e a destruição dos pequenos reinos, como já o

\footnotetext{
${ }^{27}$ Cf. Amós 3.14; 4.4; 5.5; 7.9, 13; 8.14; acerca de divindades astrais adoradas juntamente com Yahweh nos locais de culto, cf. Amós 5.26.

${ }^{28} \mathrm{Na}$ linha das descobertas etnológicas de Marshall Sahlins (2019, p. 191).

${ }^{29}$ Isto ficou demonstrado com muitos exemplos em recente pesquisa, cf. SANTOS, 2016.

${ }^{30}$ Veja as duas primeiras visões em Amós 7.1-3, 4-6; veja também Amós 3.12, que faz parte da ipssissima verba Amos. Talvez o anúncio da destruição a ser operada por Yahweh chegue como reprimenda destinada à aristocracia em geral - os "opressores" -, pois teremos que incluir as elites do setor rural - o meio ambiente de Amós -, por exemplo os latifundiários, pastoralistas e agricultores que controlavam os trabalhadores produtivos e sua força de trabalho como diaristas.
} 
expusemos. A questão passa a ser solucionar o problema econômico no âmbito da justiça que opera com códigos próprios e funciona com fórum punitivista, cujos juízes são operadores de injustiça. Daí, o vidente adquire nova função, mas teologicamente mantém-se na política da sua época.

Em certo aspecto, essa nova função, a saber, a atividade do vidente como intercessor, é mais uma representação no contexto dos conflitos de líderes em Israel Norte. Schmid (2013, p. 123) nota que "inicialmente, Amós atua como intercessor", entendendo que os capítulos 7-9 compõem o manuscrito mais antigo e 7.10-17, o núcleo da profecia. Antes de Schmid, Wilson (1993, p. 243) já havia mencionado essa função do vidente - baseado em Amós 7.2-3, 5-6 - que acrescenta à tradição efraimita alguns pontos teológicos deuteronomísticos a esse vidente judaíta que protestou em Israel Norte. A nosso ver, o protesto político teria caminhado junto com a intercessão, entendendo que o vidente tinha conhecimento das ameaças externas, tanto dos arameus de Aram-Damasco quanto dos cercos das guarnições do império neoassírio nas grandes cidades da região desde os reinos de Arpad/Bit-Agushi e de Hamat. ${ }^{31} \mathrm{O}$ fim de Israel Norte prognosticado situa-se nesta circunstância militar e no movimento contra as perdas de agricultores e comerciantes.

\section{Conclusão}

Se texto normativo exerce função crítica é porque ele, apesar de atribuição e designação a determinada estrutura oficial, segue sendo produto da sociedade com várias vozes, não raro dissonantes. No Livro de Amós, vozes pós-sacerdotais apresentam-se num paralelo às premissas protodeuteronomísticas para estabelecer o contraditório nos protestos processuais de parte da elite econômica que se considerou prejudicada pela política dirigida pelo rei. Estaria na pauta a queda do reino, post eventu.

Mas em nenhum momento os enunciados são retirados do âmbito da história; foram, com efeito, muitos intérpretes de boa vontade que sobrevalorizaram a religião perspectivamente ao regime monárquico e à economia política regional. Esta pesquisa teve o objetivo de estabelecer novas categorias de agentes sociais e suas fontes históricas na abordagem dos enunciados proféticos, aproximar-se do amplo e complexo mundo da Bíblia Hebraica.

As camadas literárias redacionais e panfletos do vidente Amós e dos assim chamados "Amós" nos parecem compósitos em demasia para uma apreensão unívoca - a fluidez dos pontos de vista, o conhecimento geográfico, a consciência política, a valorização da gleba e do

\footnotetext{
${ }^{31}$ Sobre isto, veja o panfleto antimilitarismo de Amós 3.3-4.3 e o consequente prognóstico de Amós 8.2-3. REVISTA RELEGENS THRÉSKEIA - 2021 - UFPR
} 
seu produto, a formalidade do combate contra o agente opositor, a informação alcançada, a valorização da história (o terremoto como marco cronológico do livro, cultos sírios, produção de frutos raros pelo ruralista denunciante, o controle de cidades por parte de reis, a aquisição de obras de arte pelas elites etc.), a preservação das instituições, a atenção crítica às culturas, a função organizacional. Inexiste tirocínio literário! A monarquia e o culto deveriam permanecer, mas noutros moldes.

Muitos grupos populacionais continuam sendo impactados grandemente pelas maravilhosas vozes do Livro de Amós. Assim, retomando a nossa introdução, ao apresentar contrapontos historicizantes descobrimos que a tributação de bens não responde completamente a inquirição sobre o empobrecimento de camadas da população que nem eram beneficiadas por suprimento nem faziam parte das categorias da administração direta do templo e do palácio.

Era preciso buscar fontes para analisar a política internacional da qual faziam parte Aram-Damasco, Hamat e Israel Norte, os três mais importantes pequenos reinos do sul do Levante nos séculos IX e VIII, assim como destacar a presença da Assíria. A mudança da abordagem em contrapontos historicizantes levou-nos a descobrir, em plano de fundo para chegar à realidade externa, que a supressão do culto a Yahweh e a destruição dos pequenos reinos estavam fora do projeto de justiça de Yahweh em favor de grupos de produtores e comerciantes excluídos da política palacial. Enfatizemos: o problema é do âmbito de disputa de poderes. O rei como responsável pelo sistema tributário, pelo circuito comercial e pela justiça tem a última palavra, alguns seguidores do vidente tentaram impor novas regras. A nosso ver, não podemos alcançar as motivações dos protestos fora da geografia política do Levante. E esta é função exegética, também.

\section{REFERÊNCIAS}

ALONSO SCHÖKEL, Luís; SICRE DÍAZ, José Luiz. Profetas II: Ezequiel, Profetas Menores, Daniel, Baruc, Carta de Jeremias. Trad. Anacleto Alvarez. São Paulo: Paulinas, 1991.

CRÜSEMANN, Frank. עתה "Agora". Oséias 4-11 como início da profecia escrita. In: CRÜSEMANN, Frank. Cânon e história social: ensaios sobre o Antigo Testamento. Trad. Milton Camargo Mota. São Paulo: Loyola, 2009, p. 199-220.

DIJKSTRA, Meindert. The ivory beds and houses of Samaria in Amos. In: HULSTER, Izaak J. de; LeMON, Joel M. (Eds.). Image, text, exegesis: iconographic interpretation and the Hebrew Bible. London: Bloomsbury, 2016, p. 178-195. 
ELLIGER, Karl; RUDOLPH, Wilhelm (Hrsg.). Biblia Hebraica Sttutgartensia. 5. aufl. Stuttgart: Deutsche Bibelgesellschaft, 1997.

FRANKLIN, Norma. The kushite connection: the destruction of Lachish and the salvation of Jerusalem. In: SHAI, Itzhaq; CHADWICK, Jeffrey R.; HITCHCOCK, Louise; DAGAN, Amit; McKINNY, Chris; UZIEL, Joe (Eds.). Tell it in Gath. Studies in the history and archaeology of Israel. Essays in honor of Aren M. Maeir on the occasion of this sixtieth birthday. (ÄAT 90). Münster: Zaphon, 2018, p. 680-695.

GREER, Jonathan S. The cult at Tel Dan: aramean or israelite? In: BERLEJUNG, Angelika; MAEIR, Aren M.; SCHÜLE, Andreas (Eds.). Wandering aramaeans - Aramaeans outside Syria: textual and archaeological perspectives. (Leipziger Altorientalistische Studen 5). Wiesbaden: Harrassowitz Verlag, 2017, p. 3-18.

KESSLER, Rainer. História social do antigo Israel. 2. ed. Trad. Haroldo Reimer. São Paulo: Paulinas, 2010.

LIVERANI, Mario. Para além da Bíblia: história antiga de Israel. Trad. Orlando Soares Moreira. São Paulo: Paulus; Loyola, 2008.

MICHEL, Cécile. Vision du monde. In: BORDREUIL, Pierre; BRIQUEL-CHATONNET, Françoise; MICHEL, Cécile (Dir.). Les débuts de l'Histoire: civilisations et cultures du Proche-Orient ancien. Nouvelle édition revue et augmentée. Paris: Éditions Khéops, 2014, p. 242-245.

MIEROOP, Marc van de. A history of the ancient Near East: ca. 3000-323 BC. 3. ed. Malden, MA: Wiley Blackwell, 2016.

MIEROOP, Marc van de. Historia del Próximo Oriente antiguo: $c a$. 3000-323 A.E.C. Trad. Sara Arroyo y Andrés Piquer. Madrid: Trotta, 2020.

MILSTEIN, Sara J. "Who would not write?". The prophet as Yhwh's prey in Amos 3:3-8. Catholic Biblical Quarterly, Washington, D.C., v. 75, n. 3, p. 429-445, 2013.

NISSINEN, Martti. Ancient Prophecy: Near Eastern, biblical, and Greek perspectives. Oxford: Oxford University Press, 2017.

PIXLEY, Jorge. A história de Israel a partir dos pobres. 3. ed. Trad. Ramiro Mincato. Petrópolis: Vozes, 1991.

SAHLINS, Marshall. Como pensam os "nativos": sobre o capitão Cook, por exemplo. Trad. Sandra Vasconcelos. São Paulo: Editora da Universidade de São Paulo, 2019.

SANTOS, João Batista Ribeiro. Interações no campo religioso do reino norte de Yiśrā'ēl no século IX ${ }^{\circ}$ a.C.: a cultura como problema político na Bíblia hebraica (2 Reis 9-10). REVER: Revista de Estudos da Religião, São Paulo, v. 16, n. 3, p. 197-219, 2016. 
SANTOS, João Batista Ribeiro. Origens e função do profetismo no antigo Yiśrā’ēl. In: FREDERICO, Danielle Lucy Bósio (Org.). A profecia nas origens e suas recepções. São Bernardo do Campo: Editeo, 2018, p. 35-46.

SANTOS. João Batista Ribeiro. O fato religioso ao rés do chão: teoria e método para a pesquisa do campo religioso do antigo Israel. Horizonte, Belo Horizonte, v. 17, n. 53, p. 965-990, 2019a.

SANTOS, João Batista Ribeiro. Para além de Tēl Dān: os contextos e conexões dos conflitos entre aramitas e israelitas na Idade do Ferro II. Classica: Revista Brasileira de Estudos Clássicos, São Paulo, v. 32, n. 2, p. 91-114, 2019 b.

SANTOS, João Batista Ribeiro. O vidente Amós e a política: neoassírios e aramitas no quadro político dos protestos em Israel Norte no século VIII A.E.C. Perspectiva Teológica, Belo Horizonte, v. 53, n. 2, p. 441-462, 2021.

SCHMID, Konrad. História da literatura do Antigo Testamento: uma introdução. Trad. Uwe Wegner. São Paulo: Loyola, 2013.

SCHMID, Konrad. Os primórdios da religião politizada: a teologização de conceitos políticos imperiais no Israel antigo. Estudos Teológicos, São Leopoldo, v. 58, n. 2, p. 483-496, 2018.

SCHWANTES, Milton. A terra não pode suportar suas palavras: reflexão e estudo sobre Amós. São Paulo: Paulinas, 2004.

SCHWANTES, Milton. Breve história de Israel. 2. ed. ampliada. São Leopoldo: Oikos, 2008.

SCHWANTES, Milton. O direito dos pobres. São Leopoldo; São Bernardo do Campo: Oikos; Editeo, 2013.

ZWICKEL, Wolfgang. Os santuários de fronteira do Reino do Norte - imagens de touro como sinal do culto de Yahweh. In: TILLY, Michael; ZWICKEL, Wolfgang. A história religiosa de Israel: desde a pré-história até os primórdios do cristianismo. Trad. Milton Camargo Mota. São Paulo: Loyola, 2020, p. 131-134.

WILSON, Robert R. Profecia e sociedade no antigo Israel. Trad. João Rezende Costa. São Paulo: Paulinas, 1993.

YOUNGER, K. Lawson. A political history of the arameans: from their origins to the end of their polities. (SBLABS 13). Atlanta: SBL Press, 2016. 